\title{
Do Individual Risk Attitudes, Experience, and Organizational Culture Influence The Conservatism of Indonesian Auditors?
}

\author{
Agus Fredy Maradona \\ Faculty of Economics and Business, Universitas Pendidikan Nasional, Indonesia \\ email: agusfredym@undiknas.ac.id
}

DOI: https://doi.org/10.24843/JIAB.2020.v15.i01.p01

\begin{tabular}{l} 
Jurnal Ilmiah Akuntansi \\
dan Bisnis \\
(JIAB) \\
\hline Volume 15 \\
Issue 1 \\
January 2020 \\
Page 1 - 14 \\
p-ISSN 2302-514X \\
e-ISSN 2303-1018 \\
\hline ARTICLE INFORMATION: \\
\hline Received: \\
01 November 2019 \\
Revised: \\
29 November 2019 \\
Accepted: \\
08 January 2020 \\
\hline
\end{tabular}

\section{INTRODUCTION}

This study examines the factors that influence the judgement and decision of auditors when performing an audit of financial statements in Indonesia. Specifically, this study investigates the effect of individual risk attitude, experience, and organisational culture on the conservatism of auditors when performing audit procedures on items of financial statements of their clients. As the Indonesian financial accounting standards are moving closer to full adoption of the International Financial Reporting Standards (IFRS), these Indonesian standards have become more principles-based, and less rules-based, in comparison to the previous versions of the standards (Maradona \& Chand, 2018).

Principles-based accounting standards demand extensive use of professional judgements and require company managers to make a significant number of accounting estimates in their financial statements (Nobes, 2005; Bennett, Bradbury, \& Prangnell, 2006; Carmona \& Trombetta, 2008; Bradbury \& Schröder,
2012; Wehrfritz \& Haller, 2014). As managers can exercise their judgments and discretions when determining accounting estimates, and as there have been cases where auditors have been held responsible for failure to properly evaluate such estimates, there has been a growing concern by authorities over the conservatism of auditors when evaluating these judgements and estimates (see Firth, Mo, \& Wong, 2014). This issue, in turn, has also attracted growing attention in the auditing literature (Lu \& Sapra, 2009; Feldmann \& Read, 2010; Firth, Mo, \& Wong, 2014; Lennox \& Kausar, 2017).

Conservatism is one of the oldest principles in accounting and auditing (Watts, 2003; Lu \& Sapra, 2009). The Financial Accounting Standards Board (FASB) (1980) defines accounting conservatism as "a prudent reaction to uncertainty to try to ensure that uncertainties and risks inherent in business situations are adequately considered" (par. 95). In a more elaborate manner, Gray (1988) defines conservatism in the context of financial reporting as 
"a preference for a cautious approach to measurement so as to cope with the uncertainty of future events as opposed to a more optimistic, laissezfaire, risk-taking approach" (p. 8). Consistent with FASB (1980) and Gray (1988), Basu (1997) and Doupnik \& Richter (2004) argue that conservatism manifests itself in the accountants' tendency to demand a more extensive verification when recognising gains than when recognising losses, or the tendency to defer the recognition of assets and income increasing items and to accelerate the recognition of liabilities and income decreasing items.

In line with the definitions of conservatism in the accounting context, conservatism in the auditing context is defined as "the attestation of an auditor who, when in doubt, disapprove a favourable client report" (Lu \& Sapra, 2009). The opposite of auditor conservatism is auditor aggressiveness, defined as the tendency of auditors to accepts their client's favourable financial statements, even though the auditor is unsure of the statements (Lu \& Sapra, 2009). Taken as a whole, the notion of conservatism discussed in the literature suggests that conservatism emphasises a prudence approach by professional accountants or auditors when making judgements and decisions in determining the proper approaches for the measurement and recognition of financial statement items.

In the context of an independent audit of financial statements, the extant literature has suggested that conservatism of auditors is a desirable quality of the auditing practice (e.g., Chung, Firth, \& Kim, 2003; Watts, 2003; Lu \& Sapra, 2009; Chy \& Hope, 2019). One argument to support this notion is the view that sees auditor conservatism as an effective mechanism to curb management's opportunistic reporting behaviour (Watts, 2003, Lu \& Sapra, 2009). Specifically, because management has incentives to aggressively influence the numbers reported in financial statements to suit their contractual accounting needs, auditor conservatism is expected to be in place to restrain this opportunistic behaviour. The conservatism of auditors is believed to be able to contain management's aggressive reporting behaviour by insisting a careful approach to the measurement and recognition of financial items, particularly income increasing items, in the financial statements being audited (Chung et al., 2003; Watts, 2003). Studies such as Bannister \& Wiest (2001), Chung et al. (2003), Kim, Chung, \& Firth (2003), Lee et al. (2006), Elshafie (2016), Salehi,
Tarighi, \& Sahebkar (2018), and Chy \& Hope (2019) provide strong empirical evidence to support this argument by showing that companies whose independent auditors are considered more conservative demonstrate a lower tendency to engage in aggressive earnings management in the preparation and presentation of their financial statements. Overall, the auditor conservatism literature has provided a solid conception that less conservative independent auditors can lead to more aggressive financial reporting practices by company managers.

The literature on auditor conservatism has also provided insights into the determinants of conservatism of auditors when performing their professional duties (e.g. Doupnik \& Richter, 2004; Doupnik \& Riccio, 2006; Feldmann \& Read, 2010; Wehrfritz \& Haller, 2014; Griffith, Hammersley, Kadous, \& Young, 2015; Elshafie, 2016). Most of these studies focus on investigating how differences in national culture lead to differing levels of conservatism among auditors across countries, and only a small number of these studies concentrate on examining the effect of personal factors and regulatory framework on conservatism. Findings of these culture-themed studies show that auditors residing in countries whose national culture implies greater accounting value of conservatism tend to be more conservative when performing financial reporting related tasks (Doupnik \& Richter, 2004; Doupnik \& Riccio, 2006; Wehrfritz \& Haller, 2014).

In investigating the conservatism of auditors, previous studies tend to focus on the effect of national culture because there is a prevalent concept that conservatism in the accounting and auditing contexts develops from national cultural values (Gray, 1988; Radebaugh \& Gray, 2002). The national cultural values themselves are identified using Hofstede's (1980) cultural framework. As culture determines the level of conservatism in a country's national accounting system, national culture is expected to eventually shape the conservatism held by individual auditors (see Doupnik and Richter, 2004).

Although previous studies such as Doupnik \& Richter (2004), Doupnik \& Riccio (2006), and Wehrfritz \& Haller (2014) have provided important insights into the importance of national cultural values in shaping the conservatism of auditors, however, none of those studies has considered whether conservatism of auditors can also be influenced by personality traits of individual auditors or the extent 
of professional experience of the auditors. Additionally, very few of the previous studies have provided substantial attention to the role of organisational culture in determining the extent of conservatism of practising auditors. This lack of focus on personal traits, professional characteristics, and organisational culture in empirical studies about auditor conservatism is problematic as it leads to over-simplification regarding determinants of conservatism of auditors.

To fill the gap in the literature, the present study departs from the culture-accounting framework commonly used in prior studies for examining the conservatism of auditors. This study, instead, builds on the notion that auditor conservatism results from individuals' judgements and decisions; hence it can be influenced by personal, professional, and organisational characteristics (Bonner, 2008; Mactavish, McCracken, \& Schmidt, 2018). Prior empirical studies have suggested that attitude towards risk, extent of professional experience, and organisational values are among the most important determinants of an individual's decision-making behaviour in various accounting and auditing contexts (Basu, Hwang, \& Jan, 2001; Pflugrath, MartinovBennie, \& Chen, 2007; Law, 2008; Asare, Cianci, \& Tsakumis, 2009; Chen, Hou, Richardson, \& Ye, 2018; Schafer \& Schafer, 2019). The framework developed, and the evidence provided, by prior studies present the basis for using individual risk attitude, experience, and organisational culture in the development of theory and the formulation of hypotheses in the present study.

This study develops three hypotheses to examine the effects of risk attitude, experience, and organisational culture on the conservatism of auditors. The first hypothesis examines the influence of individual auditors' risk attitude on the extent of the conservatism of auditors. This hypothesis is based on a conceptual framework which suggests that risk attitude is a direct determinant of individual decisions in situations involving risk and uncertainty ( Weber, 2010; Markiewicz \& Weber, 2013; Van Winsen et al., 2016). In the auditing context, a study by Lennox \& Kausar (2017) provides empirical evidence that prudent decision-makers prefer more conservative accounting systems, while imprudent decisionmakers prefer liberal accounting systems. In line with this finding, and drawing on the frameworks of auditor conservatism (Gray, 1988; Lu \& Sapra, 2009) and risk and decision making, the present study formulates the first hypothesis as follows.

$\mathrm{H}_{1}$ : Auditors with a lower tendency to take risk are more likely to be conservative when performing audit tasks.

The second hypothesis predicts that experience will influence the extent of the conservatism of auditors. This hypothesis draws upon the findings of previous studies such as Pflugrath et al. (2007), Asare et al. (2009), Chen et al. (2018), and Schafer \& Schafer (2019) that demonstrate that there are substantial differences in the audit judgements and decisions between more-experienced and lessexperienced auditors. In particular, these studies generally find that less-experienced auditors, due to their limited knowledge and exposure to audit tasks, tend to be more cautious when applying audit procedures prescribed in the auditing standards. Based on the discussion above, the present study formulates the second hypothesis as follows.

$\mathrm{H}_{2}$ : Less experienced auditors will exhibit greater conservatism when performing audit tasks than will more experienced auditors.

The third hypothesis examines the influence of organisational culture on the extent of the conservatism of auditors. This hypothesis builds upon a theoretical framework of the different culture between international ('the big') and local ('non-big') public accounting firms and how these cultural differences influence the judgements and decisions of auditors (Chow, Harrison, McKinnon, \& Wu, 2002). Prior studies such as Basu et al. (2001) and Chung et al. (2003) provide evidence that companies that are audited by 'the big' accounting firms tend to report more conservative earnings in their financial statements than companies that are audited by "nonbig' firms. As conservatism of earnings reported by auditees may result from the conservatism of auditors (Kim et al., 2003), this study formulates the third hypothesis as follows.

$\mathrm{H}_{3}$ : Big 4 auditors will be more conservative in performing audit tasks than non-Big 4 auditors.

The remainder of this paper proceeds as follows. The next section outlines the research methods employed in this study. This section is then followed by a presentation of results and a discussion of the results. The final section provides conclusions and 
implications of this study, along with research limitations and directions for future research.

\section{RESEARCH METHOD}

Data to test the hypotheses were collected using a factorial survey administered to auditors from both Big 4 and non-Big 4 accounting firms in Indonesia. The survey was conducted in a period between July and December 2018, and was focused in the cities of Jakarta, Surabaya, and Denpasar. These are three main cities and commercial centres in Indonesia where most businesses, as well as public accounting firms, are located. In conducting the survey, initial contact was made with all the Big 4 accounting firms that operate in Indonesia (Ernst \& Young, KPMG, Deloitte, and PricewaterhouseCoopers). Meanwhile, non-Big 4 accounting firms in Jakarta, Surabaya, and Denpasar were randomly selected (using the simple random sampling technique) from the directory of Indonesian public accounting firms published by the Indonesian Institute of Certified Public Accountants.

The accounting firms were approached through email, telephone, and personal contact. The accounting firms that agreed to allow their employees to participate in the survey were sent a questionnaire. The questionnaire was then distributed to individual auditors who worked at the corresponding accounting firms. All respondents were members of either the Institute of Indonesia Chartered Accountants (Ikatan Akuntan Indonesia - IAI) or the Indonesian Institute of Certified Public Accountants (Institut Akuntan Publik Indonesia - IAPI). A total of 153 auditors participated in the survey. Of these respondents, 67 auditors (43.8 percent) were from Big 4 accounting firms and 86 auditors (56.2 percent) were from non-Big 4 accounting firms.

The variables of interest in this study are classified into dependent and independent variables. The dependent variable is the conservatism of auditor, which is measured using a hypothetical case scenario. The use of a case scenario to measure the dependent variable is in accordance to the factorial survey design employed in this study. The case scenario used to measure the dependent variable portrays a hypothetical audit setting in which respondents were required to exercise their professional judgement on an issue relating to the application of criteria prescribed in auditing standards. Specifically, the case scenario concerns an examination by auditors of the accounting estimates contained in the financial statements of an auditee, which requires respondents to pay attention to Standar Audit (SA) 540 Audit atas Estimasi Akuntansi, Termasuk Estimasi Nilai Wajar, dan Pengungkapan yang Bersangkutan stipulated in the Indonesian codified auditing standards (equivalent to Standard on Auditing 540 Auditing Accounting Estimates, Including Fair Value Accounting Estimates and Related Disclosures stipulated in the International Standards on Auditing).

Respondents were provided with information about a hypothetical audit client (a large manufacturing company) that reports a significant amount of warranty estimates in its financial statements. The hypothetical audit client is described as currently being under government scrutiny and is applying for a bank loan, hence the need for audited financial statements. The respondents were required to determine the appropriate amount of the warranty estimates based on the procedures prescribed in the relevant auditing standard (SA 540).

The case describes that the amount of warranty estimates reported by the auditee was determined based on recommendations by two expert groups: Expert Group A and Expert Group B. Expert Group A suggests that the appropriate estimation of warranty will be between 25 percent and 35 percent of sales, while Expert Group B recommends a range between 10 percent and 20 percent of sales. To introduce a risk component to the hypothetical scenario, the case underlines that the auditor of the company face potential sanctions by the Indonesian supervisory authority of the audit profession shall they fail to determine the appropriate amount of the warranty estimate.

In the case scenario, respondents were placed in the position of an auditor who was in charge for the audit of the hypothetical client, and who, in their position as an auditor, had to make a judgement on the appropriate amount of the warranty estimates. Respondents were asked to assign, in percentage terms of sales on a scale from 0 percent to 100 percent, the appropriate level of warranty estimate that should be recognised by the client in its financial statements. Respondents were informed that the appropriate estimate was required as a basis for determining the audit opinion for the client. The extent of the conservatism of auditors was operationalized as the respondents' decisions on the appropriate estimate. Because auditor conservatism refers to the tendency to reject favourable client reports (higher reported revenue or lower reported expenses) when 
uncertainty is present (Lu \& Sapra, 2009) this study regarded the auditor approval for a greater amount of warranty estimate as an indicator of higher conservatism.

Meanwhile, the independent variables in this study are individual risk attitude, experience, and organisational culture. Individual risk attitude was measured using the Domain-Specific Risk-Taking (DOSPERT) scale (Blais \& Weber, 2006). The DOSPERT scale consists of 30 questions designed to measure individuals' tendency to take or avoid risks across five domains, i.e., ethical, financial, health/safety, recreational, and social. Each of the 30 questions evaluates the extent to which a person is likely to engage in a risky activity or behaviour on a seven-point Likert scale, where 1 denotes 'extremely unlikely' and 7 denotes 'extremely likely'. For each respondent in this study, the risk propensity score was calculated by summating their responses to all 30 questions of the DOSPERT scale. A higher total score on the DOSPERT scale indicates a stronger attitude to take risk, while a lower total score on the DOSPERT scale indicates a stronger attitude to avoid risk. The DOSPERT scale has been widely used in the literature and has been shown to possess acceptable levels of validity and reliability (Rolison, et al., 2013). In the present study, the DOSPERT scale also exhibited high reliability, with a Cronbach's alpha reliability score of 0.919 .

As regards the two other independent variables, the measures were straightforward. Experience was measured based on the number of years of professional experience of respondents as professional auditors, while organisational culture was measured based on the type of accounting firm a respondent was affiliated with (Big 4 vs non-Big 4 accounting firms).

To control for the possibility that variations in auditor conservatism occur as a result of the effects of demographic and task-related variables other than the independent variables of interest, this study adds five control variables to the empirical model. These control variables include age, length of education, gender, familiarity with accounting standards, and frequency of using accounting standards at work. These control variables were chosen because previous judgement and decision making studies in various fields such as Aharoni et al. (2011), Hardies et al. (2012), Ojiako et al. (2014), Alderman (2017),
Barrainkua \& Espinosa-Pike (2018), and Rowe (2019) have shown some evidence that age, length of education, gender, familiarity with accounting standards, and frequency of using accounting standards at work may affect the extent of conservatism of auditors.

The survey questionnaire used to collect data consisted of three sections. The first section required respondents to provide demographic data such as gender, age, level of formal education, ethnicity, professional experience, and employer details, i.e., Big 4 vs non-Big 4 accounting firms. Additionally, respondents were also asked to provide information about their level of familiarity with the Indonesian accounting standards and their frequency of using the standards when doing their professional duties.

The second section of the questionnaire consisted of a measure of risk attitude based on the DOSPERT scale (Blais \& Weber, 2006). Finally, the third section of the questionnaire consisted of the hypothetical case scenario that was developed to measure the dependent variable in this study.

In addition to collecting data related to the variables of interests, the questionnaire asked respondents about their perception on the level of complexity of the case scenario on a seven-point Likert scale, where 1 denoted 'not complex' and 7 denoted 'extremely complex'. The questionnaire also asked respondents to indicate their perceived level of familiarity in dealing with the situation depicted in the case scenario on a seven-point Likert scale, where 1 denoted 'not familiar' and 7 denoted 'very familiar'. Additionally, the questionnaire asked two seven-point Likert scale questions that required respondents to indicate the extent to which they were motivated (where 1 denoted 'not at all' and 7 denoted 'extremely motivated') and the amount of effort they expended (where 1 denoted 'very little effort' and 7 denoted 'a great deal of effort') in completing the case scenario.

To test the research hypotheses, a regression model is developed. This model specifies the relationship between auditor conservatism as the dependent variables, individual risk attitude and organisational culture as the independent variables, and age, length of education, gender, familiarity with accounting standards, and frequency of using accounting standards at work as the control variables. The regression model is specified as follows. 
$\begin{aligned} \text { CONSERVATISM }= & \beta_{0}+\beta_{1} \text { RISK }+\beta_{2} \text { EXPEREINCE }+\beta_{3} \text { ORGANISATION }+\beta_{4} A G E+\beta_{5} \text { GENDER }+ \\ & \beta_{6} \text { EDUCATION }+\beta_{7} \text { FAMILIARITY }+\beta_{8} \text { FREQUENCY }+\varepsilon \ldots \ldots \ldots \ldots \ldots \ldots \ldots \ldots . . .(1)\end{aligned}$

where:

CONSERVATISM $=$ The extent of the conservatism of auditors, measured in a scale that ranges from 0 to 100 where a higher score means a greater level of conservatism.

RISK = Risk attitude of auditors, measured in a scale ranging from 30 to 210 , where a higher score denotes greater tendency to take risk.

EXPERIENCE = Auditors' extent of professional experience in the field of auditing, measured in terms of the number of years.

ORGANISATION = Organisational culture of the accounting firm at which an auditor works, which was measured as a dummy variable, coded 1 for Big 4 accounting firm and coded 2 for non-Big 4 accounting firm.

$A G E \quad=$ Age of auditors, measured in age groups (under 20 years, 20-24 years, 25-29 years, 30 34 years, $35-39$ years, $40-49$ years, 50-59 years, and 60 years or over).

GENDER = Gender of auditors, measured as a dummy variable coded 1 for male and coded 2 for female.

EDUCATION = Length of education of auditors, measured in year groups (less than 15 years, 15 years, 16 years, 17 years, 18 years or over).

FAMILIARITY = Extent of auditors' familiarity with the Indonesian accounting standards, measured in a five-point Likert scale where 1 denotes 'very unfamiliar' and 5 denotes 'very familiar'.
FREQUENCY = Auditors' extent of frequency in referring to the Indonesian accounting standards at work, measured in a fivepoint Likert scale where 1 denotes 'never' and 5 denotes 'always'.

As hypothesis testing in this study involves a regression analysis, a standard test to ensure the fulfilment of the basic assumptions of multiple regression analysis (normality of distribution of residuals, no perfect multicollinearity between independent variables, constant variance of residuals, and no serial correlation between residuals) was performed before interpreting the regression results. When interpreting the results of the regression analysis, the principal regression coefficients of interest in the empirical model are $\beta_{l}, \beta_{2}$, and $\beta_{3}$. Consistent with the research hypotheses proposed in this study, it is expected that $\beta_{1}$ should be negative, $\beta_{2}$ should be negative, while $\beta_{3}$ should be positive.

\section{RESULTS AND DISCUSSION}

A brief summary of the demographic details of the respondents is as follows. Of the total 153 respondents, 87 (56.9 percent) were males and 66 (43.1 percent) were females, of whom the majority (89 percent) had a specialisation in financial statement audit, while the rest had a specialisation in forensic accounting and fraud investigation. 62 respondents ( 40.5 percent) were between the ages of 25 and 29 years, 38 respondents ( 24.8 percent) were between the ages of 30 and 34 years, 20 respondents (13.1 percent) were between the ages of 40 and 49 years, and the remaining respondents were spread relatively unequally in the other age groups. All respondents had at least a first degree in accounting from a higher education institution, and some of them had a postgraduate degree in accounting or other businessrelated fields. 130 respondents held the Indonesian Chartered Accountant qualification, and the remaining 23 respondents were Certified Public Accountants (CPAs) of Indonesia.

With regard to the variables examined in this study, Table 1 presents descriptive statistics of the variables based on responses from the respondents. 
Panel A of Table 1 provides descriptive statistics for the continuous variables, while Panel B of the table presents descriptive statistics for the categorical variables.

The dependent variable in this study, i.e., the conservatism of auditor, which was measured in a scale from 0 to 100 , has a mean score of 25.794 and a median score of 25 . This signifies that, as intended, respondents in this study provided responses that were anchored to the expert recommendations as depicted in the case scenario. Meanwhile, individual risk attitude, which was measured in scale from 30 to 210 , has a mean score of 97.581 and a median score of 99, implying that Indonesian auditors who participated in this study had a relatively medium to weak attitude towards taking risk. Most of the respondents who participated in this study were nonBig 4 auditors, consistent with the structure of the Indonesian auditing profession environment which is dominated by non-Big 4 accounting firms. Further, the descriptive statistics show that the sample respondents had significant professional experience $($ mean $=7.728$ years, median $=6)$. This is a logical consequence of the sampling criteria that required respondents, among other things,

Table 1. Descriptive Statistics

\begin{tabular}{|c|c|c|c|c|c|}
\hline Variable & Mean & Median & Minimum & Maximum & $\begin{array}{l}\text { Standard } \\
\text { deviation }\end{array}$ \\
\hline \multicolumn{6}{|c|}{ Panel A: Continuous variables } \\
\hline CONSERVATISM & 25.794 & 25 & 5 & 50 & 9.078 \\
\hline$R I S K$ & 97.581 & 99 & 36 & 189 & 30.894 \\
\hline EXPERIENCE & 7.728 & 6 & 1 & 27 & 5.190 \\
\hline FAMILIARITY & 4.010 & 4 & 1 & 5 & 0.618 \\
\hline FREQUENCY & 4.080 & 4 & 2 & 5 & 0.827 \\
\hline Variable & & & & Frequency & $(\%)$ \\
\hline \multicolumn{6}{|c|}{ Panel B: Categorical variables } \\
\hline \multicolumn{6}{|c|}{ ORGANISATION } \\
\hline$=1$ & Big 4 acc & ing firm & & 67 & 43.8 \\
\hline$=2$ & Non-Big & counting firm & & 86 & 56.2 \\
\hline \multicolumn{6}{|l|}{$A G E$} \\
\hline$=1$ & Under 20 & & & 0 & 0 \\
\hline$=2$ & 20-24 yea & & & 11 & 7.2 \\
\hline$=3$ & $25-29$ yea & & & 62 & 40.5 \\
\hline$=4$ & $30-34$ yea & & & 38 & 24.8 \\
\hline$=5$ & 35-39 yеа & & & 12 & 7.8 \\
\hline$=6$ & $40-49$ yea & & & 20 & 13.1 \\
\hline$=7$ & $50-59$ yеа & & & 7 & 4.6 \\
\hline$=8$ & 60 years & & & 3 & 2.0 \\
\hline \multicolumn{6}{|l|}{ GENDER } \\
\hline$=1$ & Male & & & 87 & 56.9 \\
\hline$=2$ & Female & & & 66 & 43.1 \\
\hline \multicolumn{6}{|l|}{ EDUCATION } \\
\hline$=1$ & Less than & jears & & 0 & 0 \\
\hline$=2$ & 15 years & & & 0 & 0 \\
\hline$=3$ & 16 years & & & 37 & 24.2 \\
\hline$=4$ & 17 years & & & 63 & 41.2 \\
\hline$=5$ & 18 years $\mathrm{c}$ & & & 53 & 34.6 \\
\hline
\end{tabular}

Source: Data Processed, 2019

to have a professional accounting qualification. The respondents appeared to be familiar with the Indonesian auditing standards ( mean $=4.010$, median $=4)$ and to frequently refer to the standards when performing their professional duties.

To test the research hypotheses, an ordinary least square (OLS) regression analysis was performed. All independent and control variables were entered simultaneously as predictors in the OLS regression model. An initial test of the classical assumptions of OLS regression showed that the regression equation based on the present study's data satisfied the normality assumption (the regression had a normal distribution of residuals), as well as the no multicollinearity, the no heteroscedasticity, and the no autocorrelation assumptions. Results of the 
regression analysis that are used to evaluate the research hypotheses are presented in Table 2.

Table 2. shows that the OLS regression model has a good fit with an F-statistic of 3.268 and a corresponding p-value of 0.002 (statistically significant at the 1 per cent level), implying the suitability of the regression model specified in this study. Further, the model has an $\mathrm{R}^{2}$ of 0.154 , which shows that the independent and control variables included in the model explain 15.4 per cent of the variations in the conservatism of auditors.

With regard to the hypotheses, the first hypothesis proposed in this study $\left(\mathrm{H}_{1}\right)$ predicted that auditors with a smaller tendency to take risk would be more conservative when performing audit tasks. The regressions results reported in

Table 2. Regression Results

\begin{tabular}{lcccc}
\hline Variable & Expected sign & Coefficient & t-statistic & $\begin{array}{c}\text { Probability } \\
\text { (one-tailed) }\end{array}$ \\
\hline Intercept & & & & 0.000 \\
RISK & - & 33.911 & 4.656 & $0.012^{* *}$ \\
EXPERIENCE & - & -0.057 & -2.281 & $0.005^{* * *}$ \\
ORGANISATION & + & -0.641 & -2.647 & 0.264 \\
AGE & - & 0.991 & 0.634 & 0.470 \\
GENDER & + & -0.072 & -0.076 & 0.464 \\
EDUCATION & - & 0.134 & 0.091 & 0.268 \\
FAMILIARITY & + & -0.620 & -0.620 & 0.459 \\
FREQUENCY & + & 0.140 & 0.105 & 0.229 \\
F-statistic & 3.268 & 0.718 & 0.744 & \\
$\mathrm{R}^{2}$ & 0.154 & (two-tailed $\left.\mathrm{p}=0.002^{* * *}\right)$ & \\
Source: Data Processed, 2019 & & &
\end{tabular}

'Table 2. show that the coefficient for the variable $R I S K$ is negative and statistically significant at the 5 per cent level ( $\beta=-0.057 ; t=-2.281, p=$ 0.012 ), indicating that there is a negative influence of individual risk attitude on the extent of conservatism of auditors. This finding, therefore, supports the prediction of $\mathrm{H}_{1}$. Next, the second hypothesis in this study $\left(\mathrm{H}_{2}\right)$ predicted that auditors who have less professional experience would be more conservative when conducting audit. Table 2 shows that the regression coefficient for the variable EXPERIENCE is negative and statistically significant at the 1 percent level $(\beta=-0.641 ; t=-2.647 ; p=$ $0.005)$. This finding demonstrates that there is a negative influence of experience on auditor conservatism, which is consistent with the prediction of $\mathrm{H}_{2}$. Meanwhile, with regard to the third hypothesis $\left(\mathrm{H}_{3}\right)$, the results reported in Table 2 are not consistent with the prediction. $\mathrm{H}_{3}$ predicted that Big 4 auditors, due to their organisational culture, would be more conservative than non-Big 4 auditors when making audit judgements and decisions. Table 2 shows that the coefficient for the variable ORGANISATION is not significant ( $\beta=0.991 ; t=0.634 ; p=0.264$ ), implying that the organisational culture of an accounting firm does not influence the extent of conservatism of auditors who work at the particular firm.
Regarding the control variables, the regression results demonstrate that none of the coefficients for the control variables in the model ( $A G E, G E N D E R$, EDUCATION, FAMILIARITY, and FREQUENCY) was statistically significant at the 1 per cent, 5 per cent, or 10 per cent levels. This suggests that age, gender, and length of formal education of auditors, as well as the auditors' extent of familiarity with auditing standards and frequency in using them in practice, do not influence their conservatism when making audit judgements and decisions.

To test for the robustness of the findings reported above, this study conducted a sensitivity analysis using two alternative regression models. In the first alternative model, the study used an alternative measure for individual risk attitude. That is, the measure of individual risk attitude was changed from the tendency to take or avoid risk across five domains (i.e., ethical, financial, health/safety, recreational, and social) to the tendency to take or avoid risk only in the financial domain (hereinafter labelled financial risk attitude). This alternative measure for individual risk attitude was proposed because there are two different notions in the literature regarding the appropriate way of measuring individual risk attitude (Weber, 2010; Maart-Noelck \& Musshoff, 2014; Van Winsen et al., 2016; Gürdal, 
Kuzubap, \& Saltoðlu, 2017). The first notion considers risk attitude as a stable, dispositional characteristic of an individual that is consistent across situations. Under this concept, the tendency to take or avoid risk is argued to develop from an individual's personality; thus, differences in individual tendencies towards risk-taking represent personality dissimilarities between individuals (Van Winsen et al., 2016; Gürdal et al., 2017). This notion provides a foundation for cross-domain measures of risk attitude such as the DOSPERT scale (Blais \& Weber, 2006) that was employed in the original regression model in this study.

On the other hand, the second notion about risk measure suggests that risk attitude is better understood as a function of the decision situation. It is argued that an individual's tendency to take or avoid risks can be inconsistent across situations and that a person may be risk-seeking in one decision domain yet may be risk-averse in another (see Weber, 2010; Maart-Noelck \& Musshoff, 2014). This notion, therefore, implies that induvial risk attitude should be measured in a specific domain to provide a more accurate depiction of an induvial behaviour towards risk-taking. This provides support for the use of financial-risk-attitude measure in the first alternative model in this study.

This financial risk attitude was measured using the six financial domain questions in the DOSPERT scale. The range of scores on this variable is between 6 and 42, where a higher score indicates a stronger attitude towards taking financial risk, and vice versa. The independent and control variables in the first alternative regression model are the same as those specified in the original model. The first alternative model is specified as follows:

$$
\begin{aligned}
& \text { CONSERVATISM }=\beta_{0}+\beta_{l} \text { FINANCIAL_RISK }+\beta_{2} \text { EXPERIENCE }+\beta_{3} \text { ORGANISATION }+ \\
& \beta_{4} A G E+\beta_{5} \text { GENDER }+\beta_{6} \text { EDUCATION }+\beta_{7} \text { FAMILIARITY }+ \\
& \beta_{8} F R E Q U E N C Y+\varepsilon
\end{aligned}
$$

In the above model, FINANCIAL_RISK denotes auditors' risk attitude towards taking or avoiding financial risk, measured in a scale ranging from 6 to 42 , where a higher score indicates greater tendency to take financial risk. Meanwhile, other variables are as previously defined. Results of the regression analysis based on the first alternative model are

\begin{tabular}{|c|c|c|c|c|}
\hline Variable & Expected sign & Coefficient & t-statistic & $\begin{array}{l}\text { Probability } \\
\text { (one-tailed) }\end{array}$ \\
\hline Intercept & & 37.580 & 5.842 & $0.000 * * *$ \\
\hline FINANCIAL_RISK & - & -0.485 & -5.441 & $0.000 * * *$ \\
\hline EXPERIENCE & - & -0.708 & -3.150 & $0.001 * * *$ \\
\hline ORGANISATION & + & 1.619 & 1.143 & 0.128 \\
\hline$A G E$ & + & 0.085 & 0.097 & 0.462 \\
\hline GENDER & - & -0.036 & -0.027 & 0.489 \\
\hline EDUCATION & - & -0.793 & -0.856 & 0.197 \\
\hline FAMILIARITY & - & -0.260 & -0.213 & 0.416 \\
\hline FREQUENCY & + & 0.861 & 0.963 & 0.169 \\
\hline F-statistic & 6.746 & \multirow{2}{*}{\multicolumn{3}{|c|}{$($ two-tailed $\mathrm{p}=0.000 * * *)$}} \\
\hline $\mathrm{R}^{2}$ & 0.273 & & & \\
\hline
\end{tabular}
reported in Table 3.

Table 3. Regression Results of the First Alternative Model

Source: Data Processed, 2019

As reported in Table 3, the coefficient for the variable FINANCIAL_RISK is negative and statistically significant at the 1 per cent level $(\beta=$ $0.485 ; t=-5.441, p=0.000)$, indicating that there is a negative influence of financial risk attitude on the auditor conservatism. This finding implies that the negative influence of individual risk attitude reported in this study is consistent across the different approaches to the measurement of risk attitude. This result, therefore, supports the robustness of the finding on $\mathrm{H}_{1}$. As regards to the other independent variables and the control variables included in the first alternative model, the results reported in Table 3 do not lead to different conclusions from those based on the main analysis. 
Meanwhile, in the second alternative model, the study included four additional control variables. Recall that the survey questionnaire used in this study collected data on, apart from the main variables, respondents' perceptions about the case scenario. Specifically, the questionnaire also asked how motivated the respondents were when working on the case, how much effort they spent on the case, whether the case was complex for them, and whether they were familiar in dealing with situations depicted in the case scenario. The four additional control variables were added to the regression model because the literature on judgement and decision making suggests that the characteristics of tasks can influence the judgments and decisions of auditor (Bonner, 2008), although there is limited evidence to support this argument. The first alternative model is specified as follows.

$$
\begin{aligned}
& \text { CONSERVATISM }=\beta_{0}+\beta_{1} \text { RISK }+\beta_{2} \text { EXPERIENCE }+\beta_{3} \text { ORGANISATION }+\beta_{4} A G E+ \\
& \beta_{5} \text { GENDER }+\beta_{6} \text { EDUCATION }+\beta_{7} \text { FAMILIARITY }+\beta_{8} \text { FREQUENCY }+ \\
& \beta_{9} \text { MOTIVATION_CASE }+\beta_{10} \text { EFFORT_CASE }+\beta_{11} \text { COMPLEXITY_CASE } \\
& +\beta \hat{a}_{12} \text { FAMILIARITY_CASE }+\varepsilon
\end{aligned}
$$

In the above model, MOTIVATION_CASE represents the extent to which auditors are motivated to work on the case scenario, measured on a sevenpoint Likert scale where 1 denotes 'not at all' and 7 denotes 'extremely motivated'; EFFORT_CASE represents the amount of effort expended by auditors in completing the case scenario, measured on a seven-point Likert scale where 1 denotes 'very little effort' and 7 denotes 'a great deal of effort'; COMPLEXITY_CASE represents auditors' perceptions on the level of complexity of the case scenario, measured on a seven-point Likert scale where 1 denotes 'not complex' and 7 denotes 'extremely complex'; FAMILIARITY_CASE represents auditors' perceived level of familiarity in dealing with the situation depicted in the case scenario, measured on a seven-point Likert scale where 1 denotes 'not familiar' and 7 denotes 'very familiar'. Meanwhile, other variables are as previously defined. Results of the regression analysis

\begin{tabular}{|c|c|c|c|c|}
\hline Variable & Expected sign & Coefficient & t-statistic & $\begin{array}{l}\text { Probability } \\
\text { (one-tailed) }\end{array}$ \\
\hline Intercept & & 35.473 & 4.499 & $0.000 * * *$ \\
\hline RISK & - & -0.061 & -2.409 & $0.009 * * *$ \\
\hline EXPERIENCE & - & -0.682 & -2.812 & $0.003 * * *$ \\
\hline ORGANISATION & + & 1.859 & 1.154 & 0.126 \\
\hline$A G E$ & + & 0.081 & 0.085 & 0.466 \\
\hline GENDER & + & 0.412 & 0.267 & 0.395 \\
\hline EDUCATION & - & -1.195 & -1.159 & 0.124 \\
\hline FAMILIARITY & + & 0.143 & 0.104 & 0.459 \\
\hline FREQUENCY & + & 0.612 & 0.630 & 0.265 \\
\hline MOTIVATION_CASE & - & -0.367 & -0.379 & 0.353 \\
\hline EFFORT_CASE & - & -1.409 & -1.362 & $0.087^{*}$ \\
\hline COMPLEXITY_CASE & + & 1.039 & 1.557 & $0.061^{*}$ \\
\hline FAMILIARITY_CASE & + & 0.878 & 1.388 & $0.083 *$ \\
\hline F-statistic & 2.623 & \multirow{2}{*}{\multicolumn{3}{|c|}{$($ two-tailed $\mathrm{p}=0.003 * * *)$}} \\
\hline $\mathrm{R}^{2}$ & 0.184 & & & \\
\hline
\end{tabular}
based on the second alternative model are reported in Table 4.

Table 4. Regression Results of the Second Alternative Model

Source: Data Processed, 2019

As shown in Table 4., the regression coefficients for the variables RISK and EXPERIENCE remain negative and significant, while the coefficient for the variable ORGANISATION remains insignificant, all of which are consistent with findings from the main model. These results, therefore, add support to the conclusions on $\mathrm{H}_{1}, \mathrm{H}_{2}$, and $\mathrm{H}_{3}$. Further, the findings on the five original control variables also show that these control variables are not significant determinants of auditor conservatism, consistent with results from the main model. As regards the four additional control variables, the findings reported in 
Table 3 shows that the coefficient for the variable EFFORT_CASE is negative and significant at the 10 per cent level $(\beta=-1.409 ; t=-1.362, p=0.087)$, suggesting that the more motivated the auditors are in working on the case scenario, the less conservative their responses are. Further, the coefficients for the variables COMPLEXITY_CASE $(\beta=1.039 ; t=1.557$, $p=0.061)$ and FAMILIARITY_CASE $(\beta=0.878 ; t$ $=1.388, p=0.083$ ) are positive and significant at the 10 per cent level, suggesting that auditors who perceive the case scenario to be complex and are more familiar with it tend to exhibit greater conservatism. Meanwhile, the coefficient for the variable MOTIVATION_CASE is not significant, implying that the extent to which auditors are motivated to complete the case scenario does not affect their responses.

Considered overall, the results of the regression analyses (both main and sensitivity tests) provide important insights into the role of individual risk attitude and professional experience in influencing the level of conservatism of auditors when performing audit-related tasks. In particular, the result that shows that auditors with a lower tendency to take risk tend to make a more conservative audit decision than auditors with a greater tendency to take risk implies that in an audit situation involving uncertainty, auditors assess the level of risk in the situation and make relevant decisions based on their perceptions of the risk level and individual predisposition towards taking or avoiding risk. With a specific reference to the audit on accounting estimates as depicted in the case scenario employed in this study, this finding suggests that although auditors have referred to the same auditing standard (SA 540), their audit conclusion may differ due to differences in their attitude towards risk. The finding on risk attitude reported in this study appears to be consistent with the results of prior studies examining risk attitude in the auditing and other contexts (e.g., Weber, 2010; Van Winsen et al., 2016), providing further evidence to support the notion that judgements and decisions of individuals in situations involving risk and uncertainty are shaped by the individuals' attitude towards risk.

The finding of this study that shows that experience negatively influences auditor conservatism are also consistent with findings of previous studies, particularly those by Pflugrath et al. (2007), Asare et al. (2009), Chen et al. (2018), and Schafer \& Schafer (2019). This finding, in particular, implies that auditors lose their prudence as they gain tenure in the profession and become accustomed to performing typical audit tasks such as evaluating accounting estimates. This diminishing cautiousness also suggests that tenure and experience can curb auditors' propensity to act critically when evaluating audit evidence. Further, the negative influence of auditors and conservatism can also suggest that novice auditors, in the absent of adequate practical knowledge, will choose to be conservative when responding to audit situations. This may incorrectly lead to excessive conservatism when the learning curve of the auditors is long.

Meanwhile, the failure of this study to find evidence of the association between auditor conservatism and organisational culture (as defined by the type of accounting firm, i.e., Big 4 vs non-Big 4) suggests that organisational factors may have weaker influence on auditors' judgements and decisions compared to personal characteristics. While the differences between Big 4 and non-Big 4 firms are often used in the literature as a proxy for audit quality, the finding of this study suggests that those differences may not be able to create dissimilarity in the ways auditor apply procedures prescribed in the auditing standards. Furthermore, the insignificant differences in auditor conservatism between Big 4 and non-Big 4 auditors may imply that Indonesian auditors develop their knowledge and expertise following universal methods set by the audit professional association, which apply similarly to every accounting firms regardless of their type and size.

The findings on the control variables examined in this study also warrant attention. The results that demonstrate that the measure of auditor conservatism employed in this study can be affected by the auditors' perceptions of the effort they spend working on the measure, the complexity of the measure, and their familiarity with the measure insinuate that task-related variables are important determinants of judgements and decisions of auditors. This notion is consistent with the judgment and decision-making framework proposed by Bonner (2008), which puts task characteristics as a critical factor that can shape the quality of judgments and decisions.

\section{CONCLUSION}

Auditor conservatism is regarded as a desirable quality of the auditing practice as it can restrain management's aggressive reporting behaviour by insisting on prudence approaches to financial 
reporting. While studies have shown that national cultural values can explain differences in conservatism among auditors, very few studies have examined how personal, professional, and organisational characteristics affect conservatism auditor conservatism. This study fills the gap in the literature by examining the factors beyond national cultural values that determine the extent of conservatism of auditors, particularly in developing countries.

This study provides novel evidence to support the notion that individual risk attitude influences the conservatism of auditors when performing audit tasks. Consistent with the expectations, this study finds that accountants who exhibit a weaker attitude towards taking risk are more conservative in performing audit tasks. Further, the results of this study also support the hypothesis that experience influences auditor conservatism. Consistent with the prediction, this study finds that more experienced auditors tend to be less conservative compared to auditors with a lesser amount of experience. Nevertheless, in contrary to expectation, the findings of this study suggest that organisational culture does not influence the extent of conservatism of auditors, in the sense that Big 4 and non-Big 4 auditors tend to have similar level of conservatism when performing their duties. Overall, this study contributes to the auditing literature by developing a risk-andconservatism framework in the auditing context and identifying risk attitude and professional experience as key personal and professional factors that determine the conservatism of auditors.

The findings of this study also provide significant practical and policy implications. First, because risk attitude has a significant effect on the extent of auditor conservatism, the application of procedures prescribed in auditing standards may not result in similar conclusion among auditors. Therefore, strategies that facilitate auditors to make consistent audit judgements and decisions in situations involving uncertainty are necessary. This finding may be of interest to professional associations of certified public accountants, regulatory bodies, and other policymakers in their efforts to ensure consistent and accurate audit judgements and decisions. Second, the results that more experienced auditors tend to be less conservative are a convincing signal to policymakers that auditors may lose their critical scrutiny abilities as they gain tenure in the profession. Therefore, professional associations of certified public accountants should ensure that the compulsory continuing professional education programs are able maintain the professional scepticism of tenured auditors.

Finally, the findings reported in this study should be interpreted in light of the following limitations. First, this study has only considered the decision of auditors when performing audit tasks on simple accounting estimates. Future research could examine the influence of risk attitude and experience on judgements and decisions of auditors in complex reporting situations that involve complicated estimates such as fair value estimates based on IFRS 13 Fair Value Measurement. Additionally, future research could explore the impact of risk attitude and experience on auditor conservatism in the context of the evaluation of disclosure of accounting information. Second, this study has examined the effect of experience on conservatism and inferred the level of knowledge of auditors based on this extent of experience. As extent of experience may not necessarily be consistent with level of knowledge, future research should specifically examine the effect of knowledge on auditor conservatism. This stream of research will provide a more holistic framework of the determinants of conservatism of auditors.

\section{REFERENCES}

Aharoni, Y., Tihanyi, L., \& Connelly, B. L. (2011). Managerial decision-making in international business: A forty-five-year retrospective. Journal of World Business, 46(2), 135-142.

Alderman, J. (2017). Does auditor gender influence auditor liability? Exploring the impact of the crime congruency effect on jurors' perceptions of auditor negligence. Advances in Accounting, $38,75-87$.

Asare, S. K., Cianci, A. M., \& Tsakumis, G. T. (2009). The impact of competing goals, experience, and litigation consciousness on auditors' judgments. International Journal of Auditing, 13(3), 223-236.

Bannister, J. W., \& Wiest, D. N. (2001). Earnings management and auditor conservatism: Effects of SEC enforcement actions. Managerial Finance, 27(12), 57-71.

Barrainkua, I., \& Espinosa-Pike, M. (2018). The influence of auditors' professionalism on ethical judgement: Differences among practitioners and postgraduate students. Revista de Contabilidad, 21(2), 176-187. 
Basu, S. (1997). The conservatism principle and the asymmetric timeliness of earnings. Journal of Accounting and Economics, 24(1), 3-37.

Basu, S., Hwang, L.-S., \& Jan, C.-L. (2001). Differences in Conservatism between Big Eight and non-Big Eight Auditors. Retrieved from https://papers.ssrn.com/sol3/papers. cfm?abstract_id $=2428836$

Bennett, B., Bradbury, M., \& Prangnell, H. (2006). Rules, principles and judgments in accounting standards. Abacus, 42(2), 189-204.

Blais, A.-R., \& E. Weber. (2006). A domain-specific risk-taking (DOSPERT) scale for adult populations. Judgment and Decision Making, 1(1), 33-47.

Bonner, S. E. (2008). Judgment and Decision Making in Accounting. Upper Saddle River, NJ: Prentice Hall.

Bradbury, M. E., \& Schröder, L. B. (2012). The content of accounting standards: Principles versus rules. The British Accounting Review, 44(1), 1-10.

Carmona, S., \& Trombetta, M. (2008). On the global acceptance of IAS/IFRS accounting standards: The logic and implications of the principles-based system. Journal of Accounting and Public Policy, 27(6), 455-461.

Chen, F., Hou, Y., Richardson, G., \& Ye, M. (2018). Auditor experience and the timeliness of litigation loss contingency disclosures. Contemporary Accounting Research, 35(2), 956-979.

Chow, C. W., Harrison, G. L., McKinnon, J. L., \& $\mathrm{Wu}, \mathrm{A}$. (2002). The organizational culture of public accounting firms: Evidence from Taiwanese local and US affiliated firms. Accounting, Organizations and Society, 27(4-5), 347-360.

Chung, R., Firth, M., \& Kim, J. B. (2003). Auditor conservatism and reported earnings. Accounting and Business Research, 33(1), 19-32.

Chy, M., \& Hope, O.-K. (2019). Real Effects of Auditor Conservatism (Rotman School of Management Working Paper No. 2801183). Retrieved from https://papers.ssrn.com/sol3/ papers.cfm?abstract id $=2801183$

Doupnik, T. S., \& E. L. Riccio. (2006). The influence of conservatism and secrecy on the interpretation of verbal probability expressions in the Anglo and Latin cultural areas. International Journal of Accounting, 41(3), 237-261.
Doupnik, T. S., \& M. Richter. (2004). The impact of culture on the interpretation of "in context" verbal probability expressions. Journal of International Accounting Research, 3(1), 120.

Elshafie, E. (2016). Determinants and consequences of auditor conservatism. Journal of Accounting, Ethics and Public Policy, 17(4), 831-876.

Feldmann, D. A., \& Read, W. J. (2010). Auditor conservatism after Enron. Auditing, 29(1), 267278.

Financial Accounting Standards Board (FASB). (1980). Statement of Financial Accounting Concepts No. 2: Qualitative Characteristics of Accounting Information. Norwalk, CT: FASB.

Firth,M.A., Mo,P.L.L., \&Wong,R. M.K.(2014).Auditors' reporting conservatism after regulatory sanctions: Evidence from China. Journal of International Accounting Research, 13(2), 1-24.

Gray, S. J. (1988). Towards a theory of cultural influence on the development of accounting systems internationally. Abacus, 24(1), 1-15.

Griffith, E., Hammersley, J., Kadous, K., \& Young, D. (2015). Auditor mindsets and audits of complex estimates. Journal of Accounting Research, 53(1), 49-77.

Gürdal, M. Y., Kuzubap, T. U., \& Saltoðlu, B. (2017). Measures of individual risk attitudes and portfolio choice: Evidence from pension participants. Journal of Economic Psychology, 62, 186-203.

Hardies, K., Breesch, D., \& Branson, J. (2012). Male and female auditors' overconfidence. Managerial Auditing Journal, 27(1), 105-118.

Hofstede, G. (1980). Culture's Consequences: International Differences in Work-Related Values. Beverly Hills, CA: Sage Publications.

Kim, J. B., Chung, R., \& Firth, M. (2003). Auditor conservatism, asymmetric monitoring, and earnings management. Contemporary Accounting Research, 20(2), 323-359.

Law, P. (2008). An empirical comparison of non-Big 4 and Big 4 auditors' perceptions of auditor independence. Managerial Auditing Journal, 23(9), 917-934.

Lee, P. J., Taylor, S. J., \& Taylor, S. L. (2006). Auditor conservatism and audit quality: Evidence from IPO earnings forecasts. International Journal of Auditing, 10(3), 183-199. 
Lennox, C. S., \& Kausar, A. (2017). Estimation risk and auditor conservatism. Review of Accounting Studies, 22(1), 185-216.

Lu, T., \& Sapra, H. (2009). Auditor conservatism and investment efficiency. The Accounting Review, 84(6), 1933-1958.

Maart-Noelck, S. C., \& Musshoff, O. (2014). Measuring the risk attitude of decision-makers: Are there differences between groups of methods and persons? The Australian Journal of Agricultural and Resource Economics, 58(3), 336-352.

Mactavish, C., McCracken, S., \& Schmidt, R. N. (2018). External auditors' judgment and decision making: An audit process task analysis. Accounting Perspectives, 17(3), 387-426.

Maradona, A. F., \& Chand, P. (2018). The pathway of transition to International Financial Reporting Standards (IFRS) in developing countries: Evidence from Indonesia. Journal of International Accounting, Auditing and Taxation, 30, 57-68.

Markiewicz, £., \& E. U. Weber. (2013). DOSPERT's gambling risk-taking propensity scale predicts excessive stock trading. Journal of Behavioral Finance, 14(1), 65-78.

Nobes, C. (2005). Rules-based standards and the lack of principles in accounting. Accounting Horizons, 19(1), 25-34.

Ojiako, U., Chipulu, M., Gardiner, P., Williams, T., Mota, C., Maguire, S., Shou, Y., \& Stamati, T. (2014). Effect of project role, age and gender differences on the formation and revision of project decision judgements. International Journal of Project Management, 32(4), 556-567.

Pflugrath, G., Martinov-Bennie, N., \& Chen, L. (2007). The impact of codes of ethics and experience on auditor judgments. Managerial Auditing Journal, 22(6), 566-589.

Radebaugh, L. H., \& S. J. Gray. 2002. International Accounting and Multinational Enterprises (5th ed.). New York, NY: John Wiley \& Sons.
Rolison, J. J., Y. Hanoch, S. Wood, \& P.-J. Liu. (2013). Risk-taking differences across the adult life span: a question of age and domain. Journals of Gerontology, Series B: Psychological Sciences and Social Sciences, 69(6), 870-880.

Rowe, S. P. (2019). Auditors' comfort with uncertain estimates: More evidence is not always better. Accounting, Organizations and Society, 76, $1-11$.

Salehi, M., Tarighi, H., \& Sahebkar, H. (2018). The impact of auditor conservatism on accruals and going concern opinion: Iranian angle. International Journal of Islamic and Middle Eastern Finance and Management, 11(4), 650-666.

Schafer, B. A., \& Schafer, J. K. (2019). Interpersonal affect, accountability and experience in auditor fraud risk judgments and the processing of fraud cues. In Advances in Accounting Behavioral Research, 22, 43-65. Somerville, MA: Emerald Publishing Limited.

Van Winsen, F., De Mey, Y., Lauwers, L., Van Passel, S., Vancauteren, M., \& Wauters, E. (2016). Determinants of risk behaviour: Effects of perceived risks and risk attitude on farmer's adoption of risk management strategies. Journal of Risk Research, 19(1), 56-78.

Watts, R. L. (2003). Conservatism in accounting Part I: explanations and implications. Accounting Horizons, 17(3), 207-221.

Weber, E. U. (2010). Risk attitude and preference. Wiley Interdisciplinary Reviews: Cognitive Science, 1(1), 79-88.

Wehrfritz, M., \& Haller, A. (2014). National influence on the application of IFRS: Interpretations and accounting estimates by German and British accountants. Advances in Accounting, Incorporating Advances in International Accounting, 30(1), 196-208. 